\title{
Distal femur kırıklarında plak ile minimal invaziv osteosentez uygulamaları
}

\section{Minimally invasive osteosynthesis with plaque in distal femur fractures}

\author{
Adil Turan, Yusuf Alper Katı, Halil Yalçın Yüksel
}

Sağlık Bilimleri Üniversitesi, Antalya Eğitim ve Araştırma Hastanesi, Ortopedi ve Travmatoloji Kliniği, Antalya

\begin{abstract}
Distal femur kırıkları, tüm kırıklar içerisinde 37/100 000, femur kırıkları içerisinde ise \%4-6 oranındadır. Minimal invaziv yöntemlerle yapılan cerrahilerde amaç; yaralanma bölgesinde minimum cerrahi hasar yaratarak, kırık parçalarının biyolojisine zarar vermeden tespit sağlamaktır. Bu nedenle, özellikle açık cerrahilerde, kaynama problemleri ile karşılaşılan parçalı kırıkların tespitinde bu yöntem sıklıkla kullanılır. Minimal invaziv cerrahi için birçok implant kullanılmaktadır. Bu yazıda, plak ile yapılan minimal invaziv osteosentez uygulamaları anlatılacaktır.
\end{abstract}

Anahtar sözcükler: minimal invaziv osteosentez; distal femur kırıkları

\section{GiRiş-ETIYOLOJi}

Distal femur kırıkları, tüm kırıklar içerisinde 37/100 000 , femur kırıkları içerisinde ise \%4-6 oranındadır. ${ }^{[1,2]}$ Bu kırıklar, yaşa göre dağılımına bakıldığında, iki farklı dönemde artış gösterir. Birinci dönem; genç, sağlıklı bireylerde görülen ve trafik kazaları, yüksekten düşme gibi yüksek enerjili travma sonucu meydana gelen hastalardan oluşur; çoğunluğu parçalı tipte kırıklardır ve yumuşak doku hasarı ile birlikte olma eğilimindedir. îkinci en sık gözlendiği dönemde ise, kırıklar osteoporotik yaşlı hastalarda ve basit düşme gibi düşük enerjili yaralanmalar sonucu meydana gelen tiptedir; genellikle spiral oblik şekilli ve daha az parçalı olarak ortaya çıkar. ${ }^{[3]}$ Son zamanlarda, özellikle yaşlı hastalarda artroplasti cerrahisinin sık yapılması nedeniyle, protez çevresi kırıklarla da sık olarak karşılaşılmaktadır. ${ }^{[4]}$

\section{SINIFLAMA}

Distal femur kırıkları ile ilgili birçok sınıflama yapılmıştır. Ancak, Müller tarafından yapılan ve daha sonra AO (Arbeitsgemeinschaft für Osteosynthesefragen)
Distal femur fractures are 37/100 000 in all fractures and $4-6 \%$ in femur fractures. The goal of minimally invasive surgery is fixation without giving damage to the biology of fracture parts by minimizing surgical damage in the injured area. Therefore, this method is frequently used in fixing the fragmented extremities, especially in open surgery with union problems. Many implants are used for minimally invasive surgery. In this article, minimally invasive osteosynthesis applications with plaque will be explained.

Key words: minimally invasive osteosynthesis; distal femur fractures

tarafından geliştirilerek Ortopedik Travma Birliği (The Orthopaedic Trauma Association-OTA) tarafindan kabul edilen AO/OTA sınıflama sistemi en sık kullanılanıdır (Şekil 1). Bu sınıflama temelde, kırı̆ı̆ı femurdaki yerleşim yerine ve parçalanma miktarına dayanmaktadır. Tedavi ve prognoz ile ilgili de bilgi verdiği için kullanışlıdır. Tip A kırıklar eklem dışı kırıklar, Tip B kırıklar kısmi eklem içi-kondil kırıkları, Tip C kırıklar ise hem metafizyel kısmı hem de eklem içini ilgilendiren kırıklar olarak tanımlanır. Bunların da her biri kendi içerisinde parçalanma miktarına ve yerleşim yerlerine göre alt gruplara ayrılır. ${ }^{[5,6]}$ Plakla minimal invaziv osteosentez uygulamaları için başlıca endikasyon Tip A, eklemi ilgilendirmeyen özellikle Tip A3 gibi parçalı metafizer kırıklar olmakla birlikte, eklem redüksiyonu için artrotominin cerrahiye eklenmesiyle, Tip B ve Tip C kırıklarda da uygulanabilmektedir.

\section{KLINIK VE RADYOLOJiK DEĞERLENDIRME}

Tüm hastalar, tam bir fizik muayene ile eşlik eden ek yaralanmalar yönünden değerlendirilmelidir. Kırı̆ı̆n

- Illetişim adresi: Dr. Adil Turan, Antalya Eğitim ve Araştırma Hastanesi, Ortopedi ve Travmatoloji Kliniği, Varlık Mh., Kazım Karabekir Cd., Muratpaşa, Antalya Tel: 0505 - 2381386 e-posta: adilturan@yahoo.com

- Geliş tarihi: 1 Eylül $2018 \quad$ Kabul tarihi: 1 Eylül 2018 


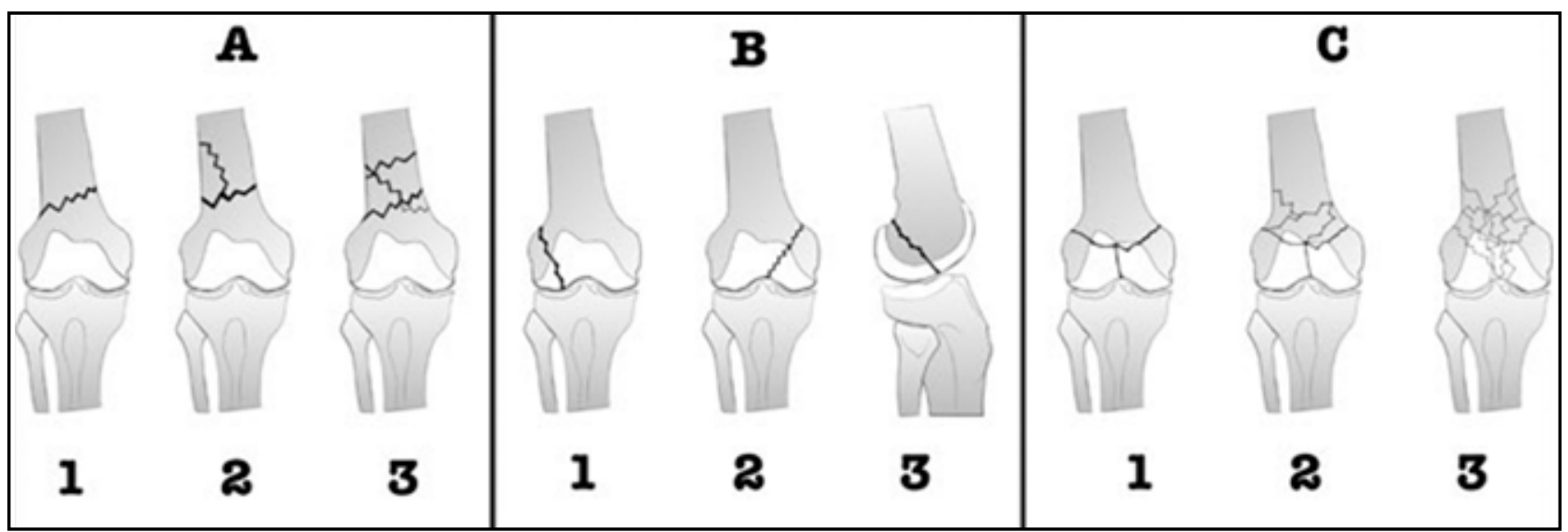

Şekil 1. Distal femur kırıklarında AO/OTA sınıflama sistemi.
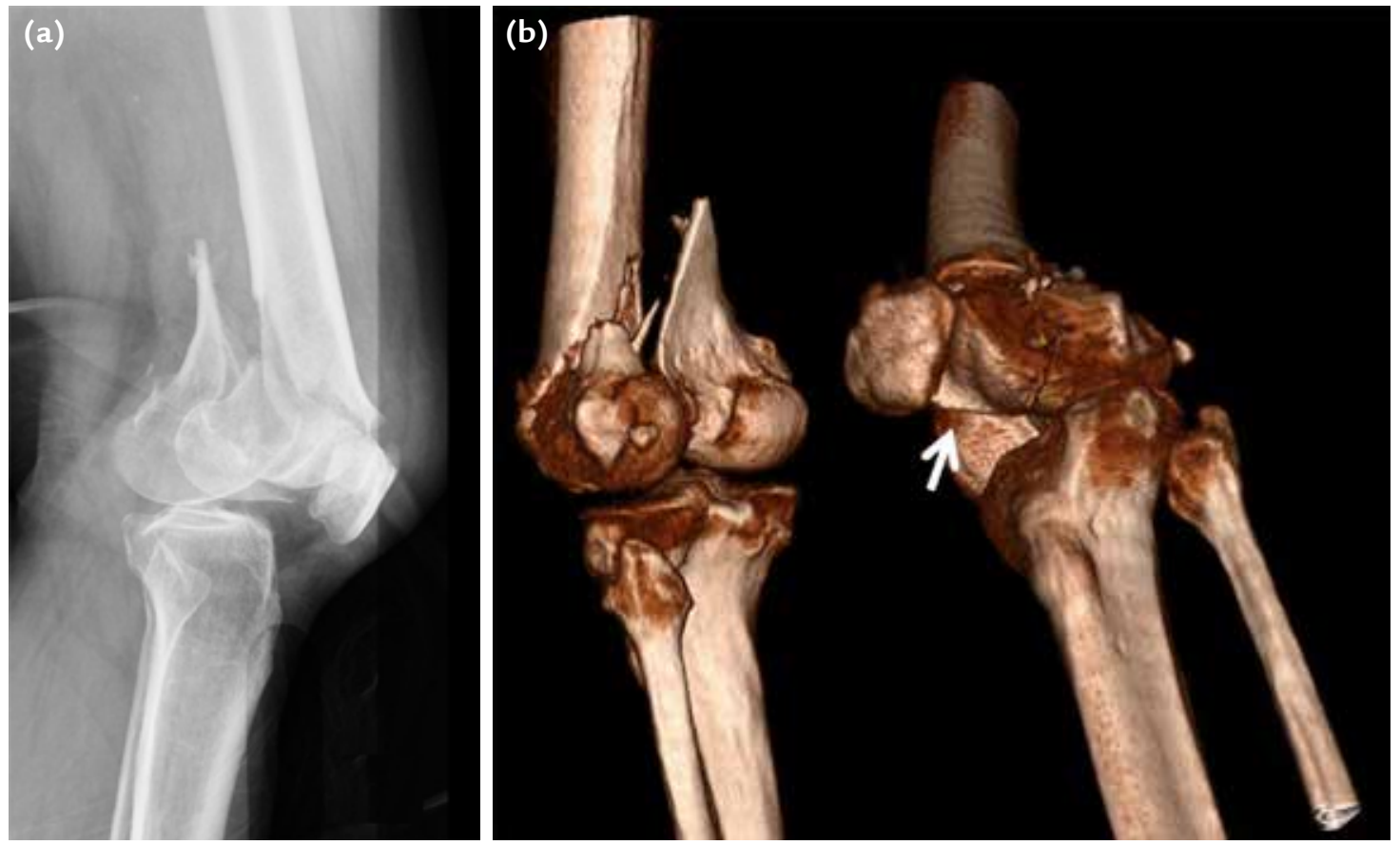

Şekil 2. a, b. Tip C3 distal femur kırığının direkt grafi (a) ve üç boyutlu tomografi görüntüsü (b). Ok ile gösterilen eklem içi koronal planda Hoffa kırı̆̆.

iyi bir şekilde tanımlanabildiği, üst ve alt eklemlerin de görüldüğü tam ön-arka ve yan grafiler mutlaka elde olmalıdır. Bu kırıklarda genellikle kısalık ve rotasyon olduğu için, ekstremitenin distalinden yapılan nazik bir traksiyon ile kırık tanımlaması daha iyi bir şekilde yapılabilir. Ayrıca, redüksiyon ile elde edilen dizilimin doğruluğunu belirlemek ve kırık ekstremite ile karşılaştırmada şablon olarak kullanmak için ihtiyaç duyulması halinde ,sağlam tarafın da grafileri çekilmelidir. Anatomik aks, mekanik aks, uzunluk gibi hastaya ait anatomik özellikler kaydedilmelidir. Özellikle yaşlı hastalarda, diz bölgesinde kırık öncesi mevcut olan artroza bağlı varus ya da valgus deformitesi, anatomik plakların yerleştirilmesindeki sorunları önceden belirlemek için dikkatli bir şekilde incelenmelidir. Eklem yüzeyini ilgilendiren kırıklarda ise, hem deplasman miktarını ve parçalanmayı değerlendirmek hem de yapılacak cerrahiyi planlamak için üç boyutlu hale getirilebilen bilgisayarlı tomografi görüntüleri kullanılır. Özellikle minimal invaziv cerrahi için çok uygun olmayan ve direkt grafilerde sıklıkla atlanabilen koronal plan kırıklarının (Hoffa kırıkları 33 B-3) tanısının konmasında üç boyutlu tomografi oldukça yararlıdır (Şekil 2). ${ }^{[7]}$ 


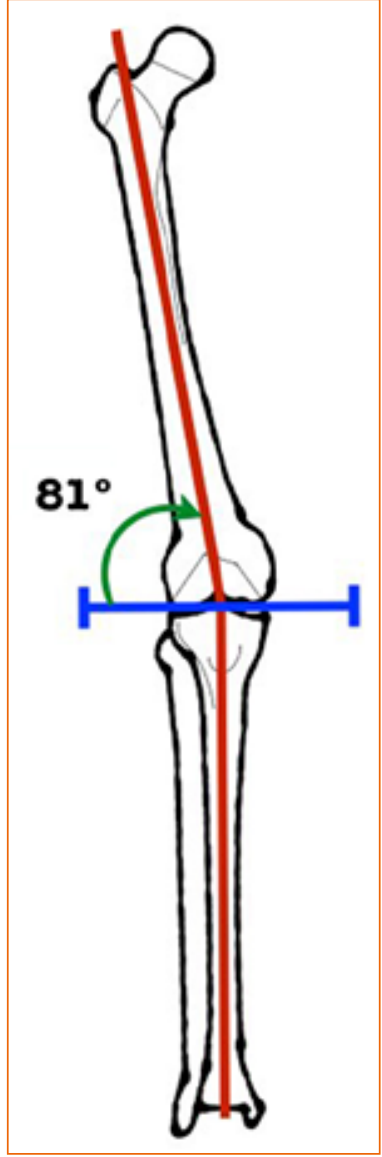

Şekil 3. Femur ve tibianın anatomik aksları ve anatomik lateral distal femoral açı.

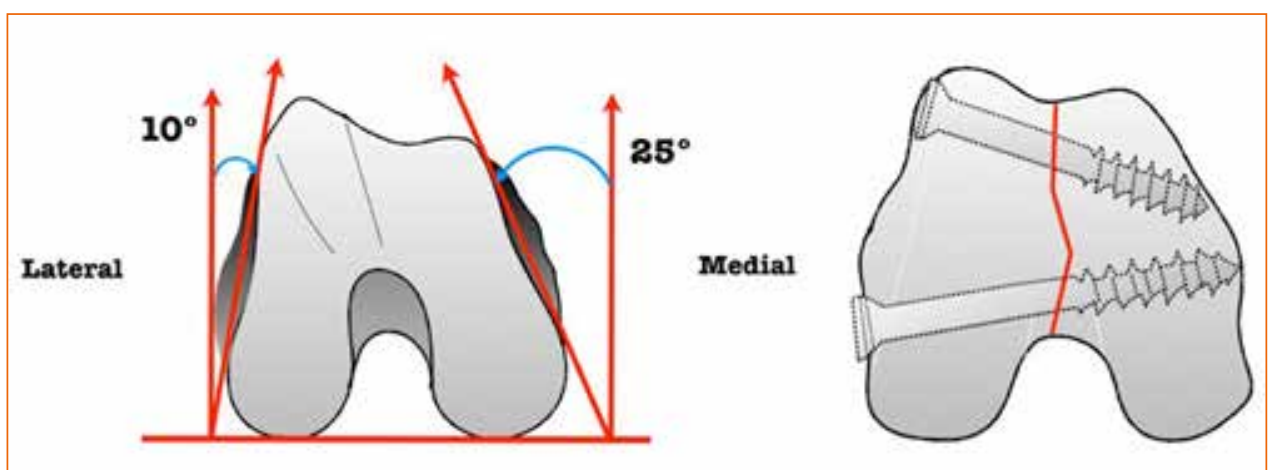

Şekil 4. Distal femur anatomisi.

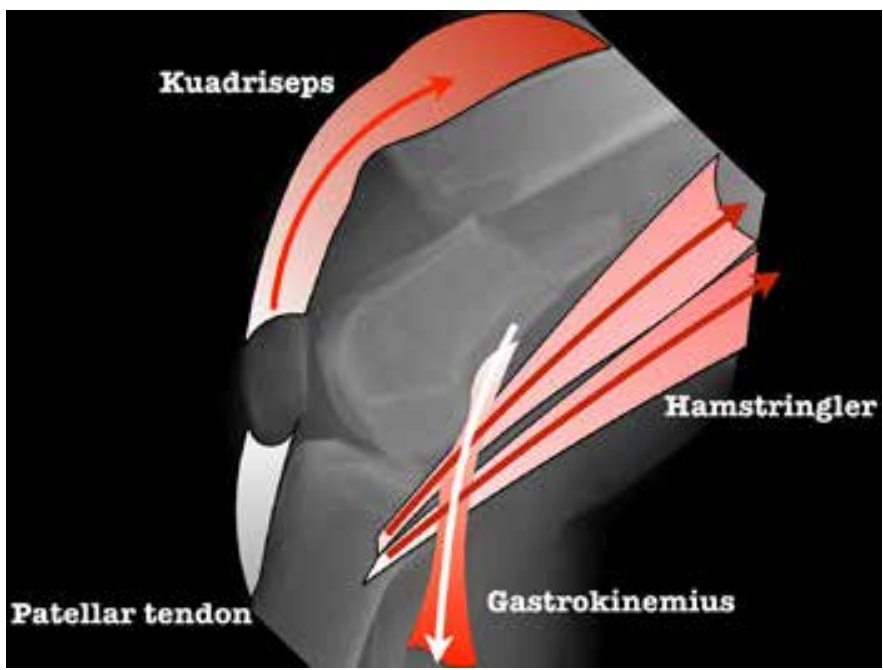

Şekil 5. Distal femur kırığı sonrası meydana gelen yer değiştirmeler ve bunlara neden olan kasların yerleşimleri.

\section{DISTAL FEMURUN ANATOMIK ÖZELLIKLERi}

Femur distal kondiler ve suprakondiler bölgeyi içerecek şekilde ifade edilen distal femoral bölge, diyafizyel bölgenin diz eklemine doğru genişlemesi ile meydana gelir. Eklem yüzünde femoral cismine göre 7-11 ${ }^{\circ}$ 'lik bir valgus açılanması vardır (Şekil 3). Bu ilişkinin korunması ekstremitenin fonksiyonu için çok önemlidir. Ayrıca, distal femur trapezoidal bir şekle sahiptir. Aksiyel planda femur lateral korteksin $10^{\circ}$ lik, mediyal korteksin ise $25^{\circ}$ lik posteriordan anteriora doğru daralan bir eğimi mevcuttur. Bu durumun bilinmesi, lateral plak yerleşimi ve ön arka skopi görüntüsü ile plak üzerinden veya dışından gönderilecek vidaların mediyal tarafta korteksi geçtikten sonra uzun kalmasına engel olmak açısından önemlidir (Şekil 4). Cerrahi sırasında alınan AP skopi görüntülerinde özellikle anterior yerleşimli vida uzunlukları, mediyal korteksten $1 \mathrm{~cm}$ kadar kısa olmalıdır. Aksi takdirde, mediyal bölgede vida penetrasyonu meydana gelebilir.
Bu kırıklarda, diz çevresinden başlayan veya o bölgede sonlanan kas yapılarının çekmesine bağlı olarak birtakım yer değiştirmeler meydana gelmektedir. Bu yer değiştirmeler, kuadriseps ve hamstring kaslarının çekmesi sonucu kısalık, adduktor kasın çekmesine bağlı varus ve gastrokinemius kasının çekmesine bağlı ekstansiyon şeklindedir (Şekil 5). Bu kasların çekme yönlerine karşı uygulanan zıt kuvvetler ya da ileride anlatılacak olan indirekt redüksiyon teknikleri ile kapalı dizilim sağlanması, minimal invaziv plaklama için önem taşımaktadır. ${ }^{[3]}$

\section{PLAKLI MINIMAL INVAZIV OSTEOSENTEZ YAKLAŞIM ENDIKASYONLARI}

Minimal invaziv yöntemlerle yapılan cerrahilerde amaç; yaralanma bölgesinde minimum cerrahi hasar yaratarak, kırık parçalarının biyolojisine zarar vermeden tespit sağlamaktır. Bu nedenle, özellikle 
açık cerrahilerde kaynama problemleri ile karşılaşılan parçalı kırıkların tespitinde bu yöntem sıklıkla kullanılmaktadır. Bu amaçla, indirekt ya da sınırlı direkt redüksiyon yöntemleri kullanılmakta ve kas dokusunun alt yüzeyi ile periost arasında açılan tünele yerleştirilen plak ile kırı̆̆ı çevreleyen yumuşak doku bütünlüğü büyük ölçüde korunmaktadır. Böylece, kırık parçaların kan akımı destekleri devam etmekte, greft gereksinimi, enfeksiyon oranları ve ameliyat sonrası ağrı azalmakta, daha iyi fonksiyonel sonuçlar elde edilmektedir. ${ }^{[8,9]}$ Bu cerrahi uygulama için özel tasarımlı yardımcı el aletleri ve implantlar geliştirilmiştir. Şekil 6 ve 7'de parçalı bir femur distal kırı̆̆ını plak üzerinden çektirme vidaları ve yine minimal invaziv olarak uygulanan redüksiyona yardımcı serklaj tellerinin kullanıldığı olgu örneği, Şekil 8'de aynı olgunun ameliyat öncesi Şekil 9'da ise ameliyat sonrası grafileri sunulmuştur.

Bu yöntem metafizyel parçalı kırıklar için daha sıklıkla kullanılmaktadır. Bu tip kırıklarda aksiyel dizilim, uzunluk ve rotasyonun düzeltilmesi yeterli olup, tam anatomik redüksiyon amaçlanmaz. Tespit ile, genellikle göreceli stabilite elde edilir. Eklem bölgesini ilgilendiren kırık varlığında ise açık redüksiyon yapılmalı, komponentlerin anatomik redüksiyonu sağlanarak mutlak stabilite elde edilmelidir. ${ }^{[10,11]}$ Ayrıca, plakla minimal invaziv osteosentez, femoral kanalın çok dar ya da deforme, periprostetik kırık gibi femoral giriş yerinin kapalı, medullanın implantla dolu olduğu ve epifizleri açık hastalar gibi durumlarda da kullanılabilmektedir.

Buna karşın, özellikle iki haftayı geçmiş kırıklarda indirekt redüksiyonun zor olması nedeniyle, damar yaralanmasının eşlik ettiği, ileri düzeyde yumuşak doku hasarı olan ve kontaminasyon riski bulunan kırıklarda uygulanmaması önerilmektedir. ${ }^{[8]}$

\section{IMPLANT SEÇiMi}

Kırığın tipine göre uygun implant seçimi, sonuçları etkileyen önemli bir basamaktır. Distal femurda plakla minimal invaziv osteosentezde kullanılabilir implant seçenekleri arasında yer alan geleneksel kilitsiz vidalı plakların, DCS'nin (dinamik kondiler vida) ve 95' lik açılı kamalı plakların artık günümüzde bu amaçla kullanımı azalmıştır. Bu implantların yerini distal femur için tasarlanmış kilitli kompresyon plakları almıştır. Distal femur için tasarlanan kilitli kompresyon plaklarının minimal invaziv uygulamayı kolaylaştırmak için hazırlanmış bir setin parçası olduğu durumlarda da bu plaklar LISS $^{\circledR}$, MISS $^{\circledR}$ vb. gibi farklı ticari isimlerle anılmaktadır. ${ }^{[3,8]}$ DCS ve açılı kamalı plak ile kilitli vidalı plak, farklı düzeylerde de olsa, açısal stabilite sağlayan implantlardır. Bu açısal stabilite sağlayan plakların tercihinde ise kırık şeklinin ve kırığın ekleme göre yerleşim yerinin ortaya çıkardığı avantaj ve dezavantajlar dikkate alınır (Şekil 10).

Bu bölgeye özel, minimal invaziv osteosentez için kullanılan, faklı firmalara ait, distal femur için dizayn edilen kilitli plaklarda aşağıda bahsedilen özelliklerin tümü ya da birkaçı bir arada bulunabilir. Bu implantlar femur anatomisine uygun olarak tasarlandıkları için, hem destek özelliği gösterir hem de redüksiyona yardımcı olabilir (Reduction Mold). ${ }^{[8]}$ Kilitli vida deliği ile birlikte kompresyon yapmaya da olanak sağlayan, bileşik vida delik yapısına sahip olan plaklar da vardır. Bunlar, düşük temas yüzeyi özelliği nedeniyle, periosta minimal basınç uygulayarak kan dolaşımını en az düzeyde etkiler. Tek yönlü (uni-aksiyel) kilitlenebilir vida deliğinden farklı şekilde çok yönlü (poli-aksiyel) uygulanabilen kilitli vida ile tespit özelliği olan implantlar da vardır. Geleneksel kilitsiz vidalı plaklardan farklı olarak kilitli vidalı plaklarda, vida plağa sabitlendiği için, plak bir internal fiksatör görevi görmekte ve açısal olarak daha stabil bir yapı oluşturmaktadır. Bu distal femur için tasarlanmış kilitli vidalı plakların bir kısmı ise, açık redüksiyon ve tespit için kullanımlarının yanı sıra, beraberinde minimal invaziv plaklamayı yapmak ve kolaylaştırmak için tasarlanmış aparatları içeren bir sisteme de uygun olma özelliğine sahiptir (Şekil 11)..$^{[8,12]}$

\section{CERRAHI TEKNIK}

Cerrahiye başlamadan önce iyi bir planlama minimal invaziv girişimler için oldukça önemlidir. Ameliyat salonuna girmeden önce radyografiler kullanılarak kırık parçaların yerleşimi, plak boyu vida sayısı ve gönderilecek vidaların plak üzerinden yerlerinin belirlenmesi cerrahi sırasında kolaylık sağlayacaktır.

Minimal invaziv plaklama tekniğinde plak ekstramedüller internal bir atel görevi göreceği için, tıpkı eksternal fiksatör ya da intramedüller çivi gibi olabildiğince uzun olmalıdır. Bu uzunluk kabaca, parçalı kırıklarda kırık boyunun üç katı, transvers kırıklarda ise 8-10 katı olarak belirtilebilir. Esnek bir tespit için bu uzun plaklara yeterli, ancak en az sayıda vida kullanılmalıdır. Osteoporotik kırıklarda kilitli vida sayıları arttırılabilir. Kırığın en distal ve en proksimal kısmına gönderilen vidalar arasındaki mesafe, çalışma mesafesi olarak adlandırılır. Uygun bir çalışma mesafesi için bu bölgedeki vida delikleri boş bırakılmalıdır. Ayrıca, plak üzerine binen stresi dağıtabilmek için, tüm vida delikleri doldurulmamalı ve kullanılan vida/plak vida delik sayısı olarak ifade edilen plak vida doygunluğu \%40 civarında olmalıdır. En proksimal vida ise, genellikle plak üzerinde stres bölgesi yaratmamak ve o bölgeden kırık oluşma riskini en aza indirmek için, tek korteks uygulanabilir. 

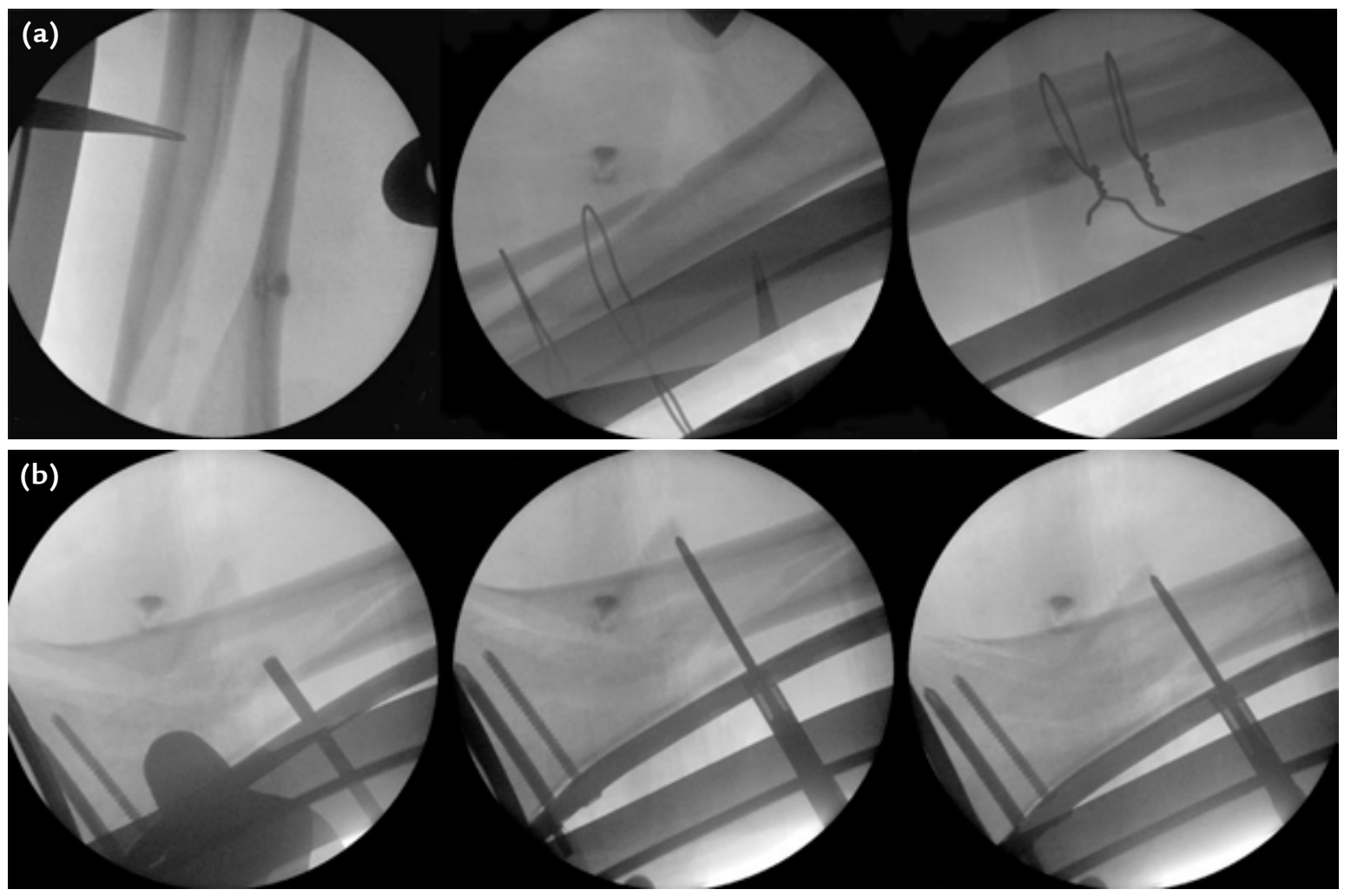

Şekil 6. a, b. Minimal invaziv olarak uygulanan serklaj telleri ile redüksiyonun sağlanması (a), Distal bölgedeki redüksiyonun ise plak üzerinden uygulanan çektirme aparatı ile yapılması (b).
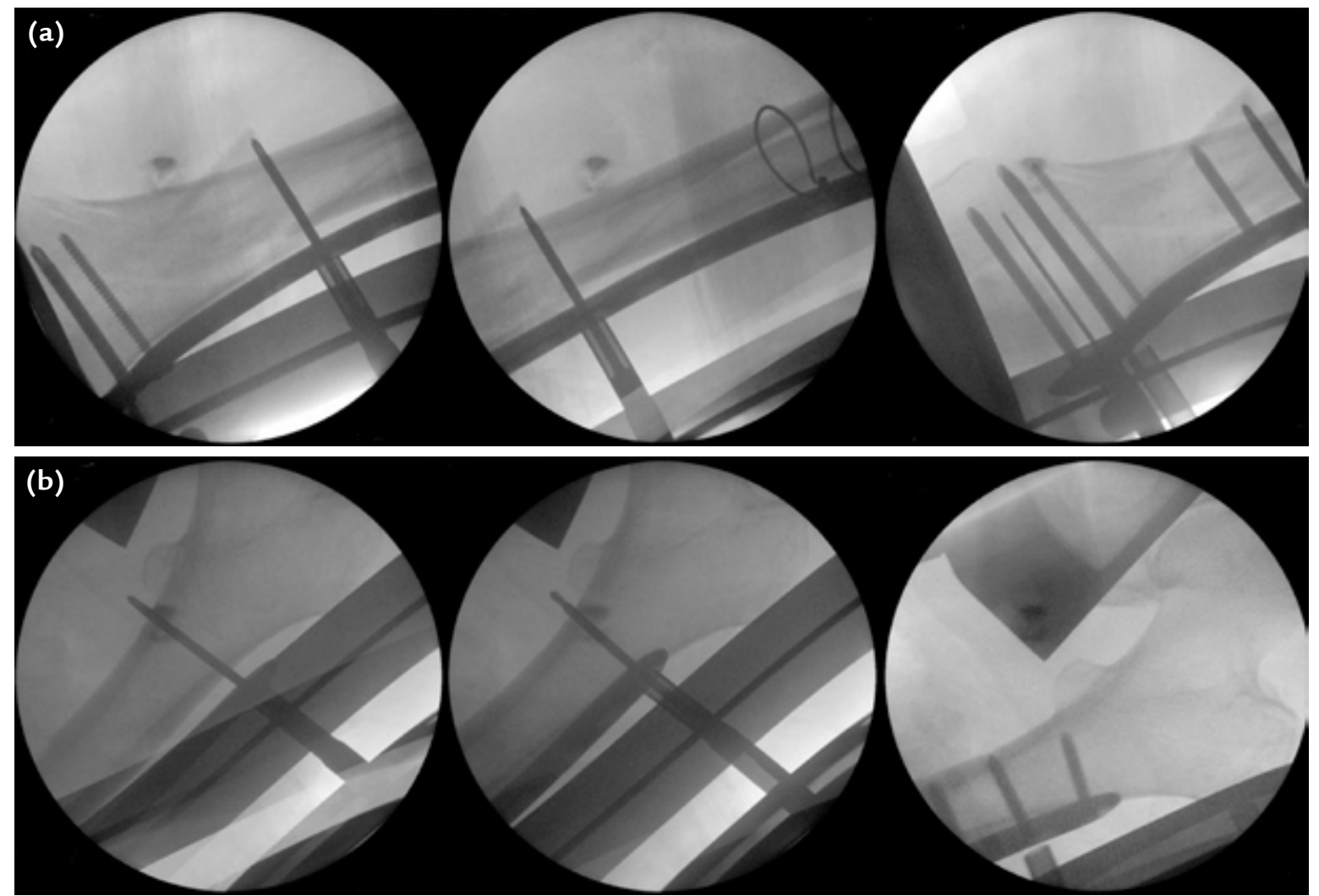

Şekil 7. a, b. Plak üzerinden yapılan redüksiyon ve plağın yerleştirilmesi ile ilgili teknikler (a, b). 


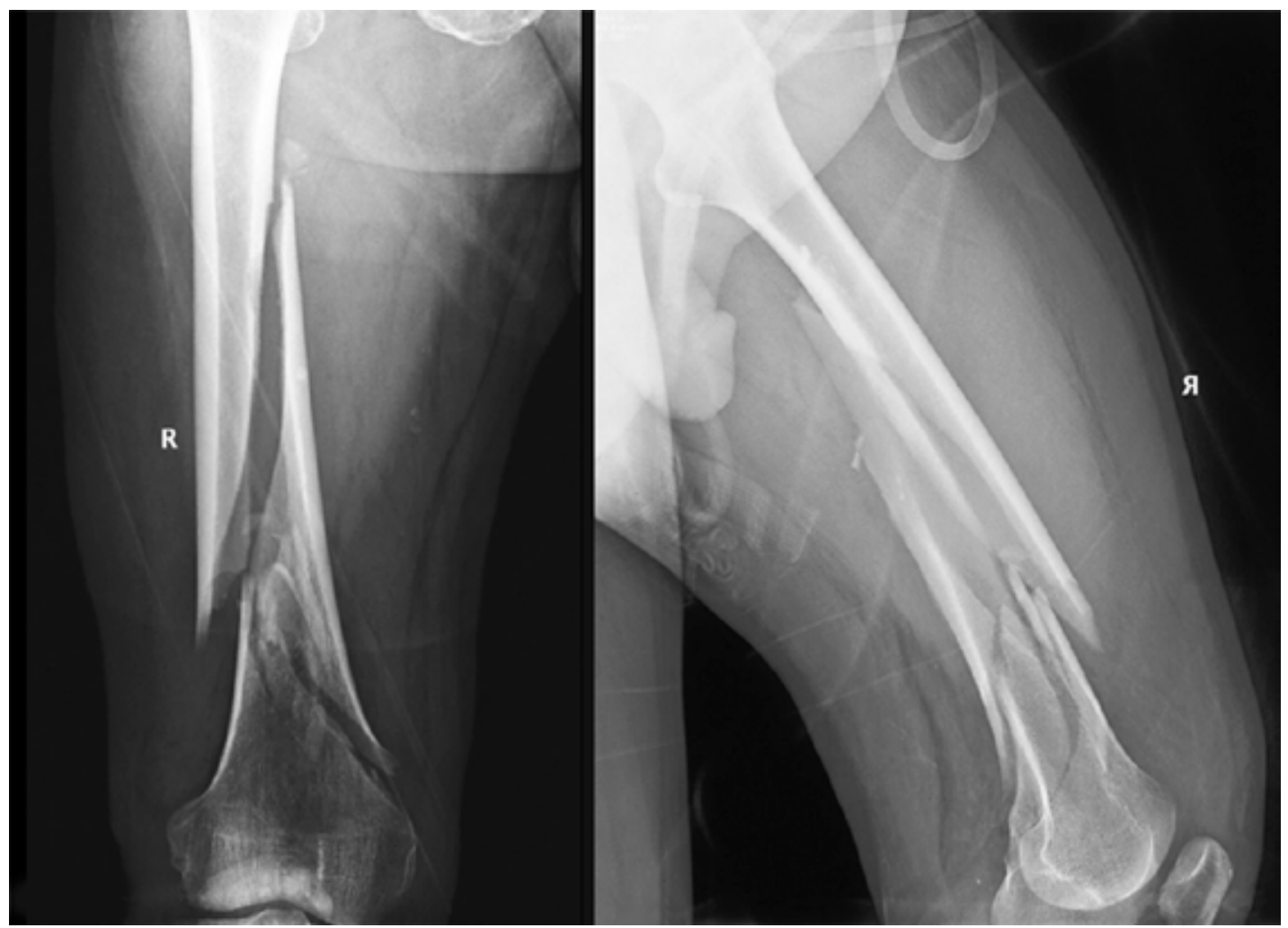

Şekil 8. Femur kırığı olgusunun ameliyat öncesi ön-arka ve yan grafileri.

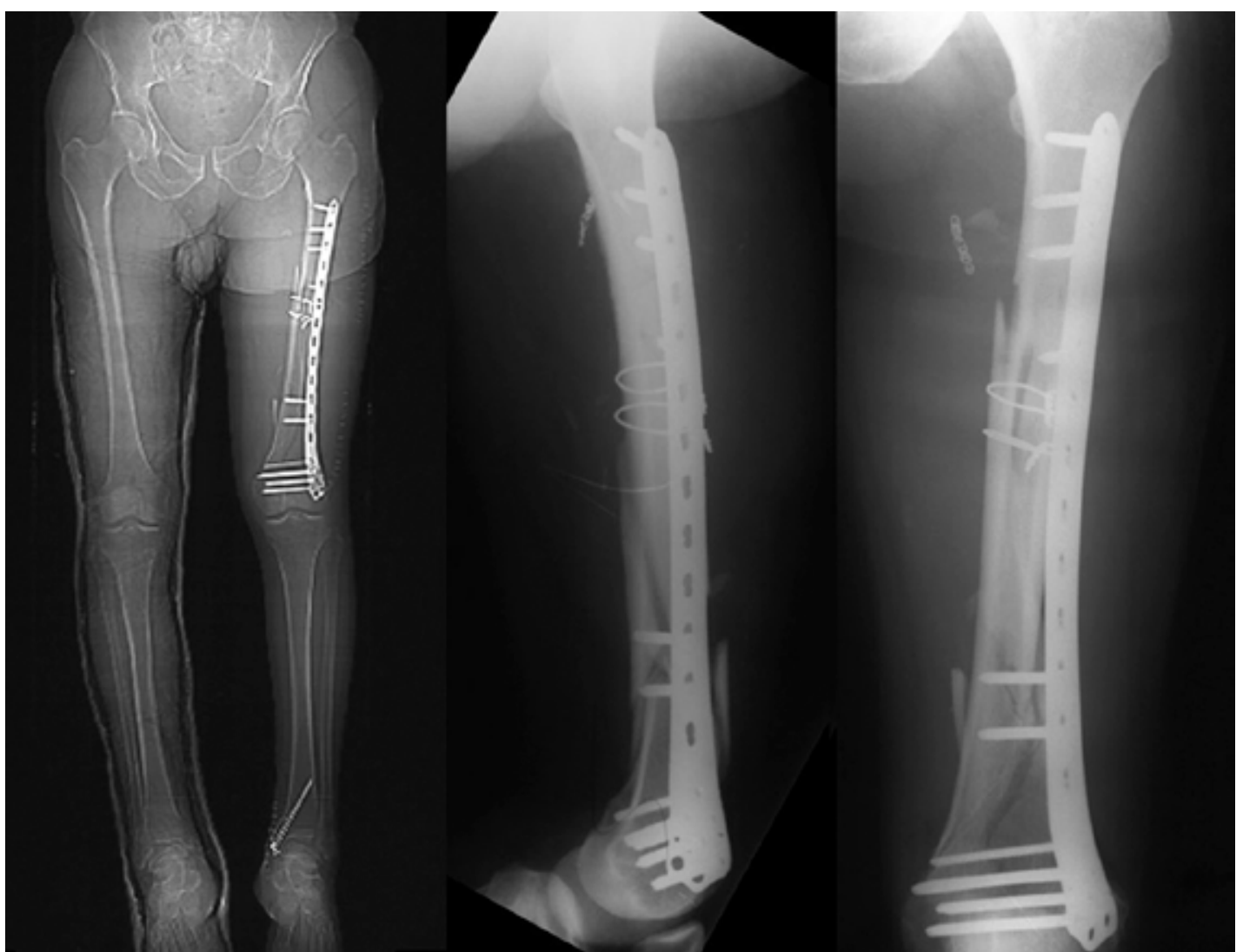

Şekil 9. Erken ameliyat sonrası ön-arka, yan ve aks grafileri. 


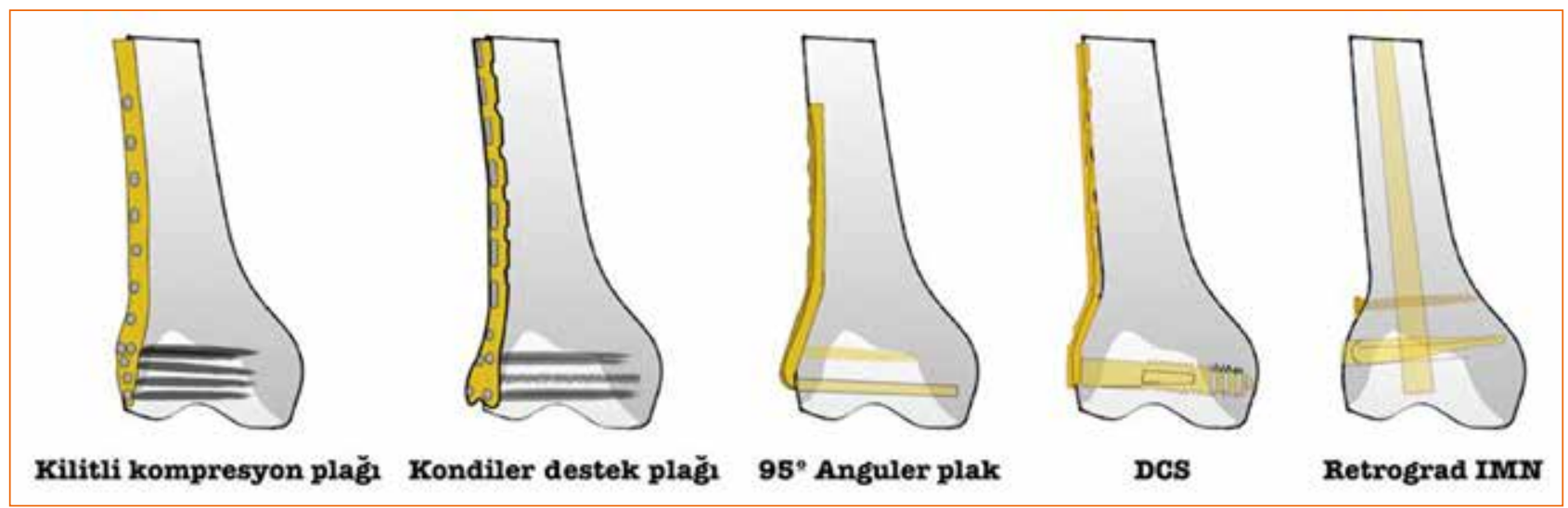

Şekil 10. Distal femur kırıklarında kullanılan implant çeşitleri.

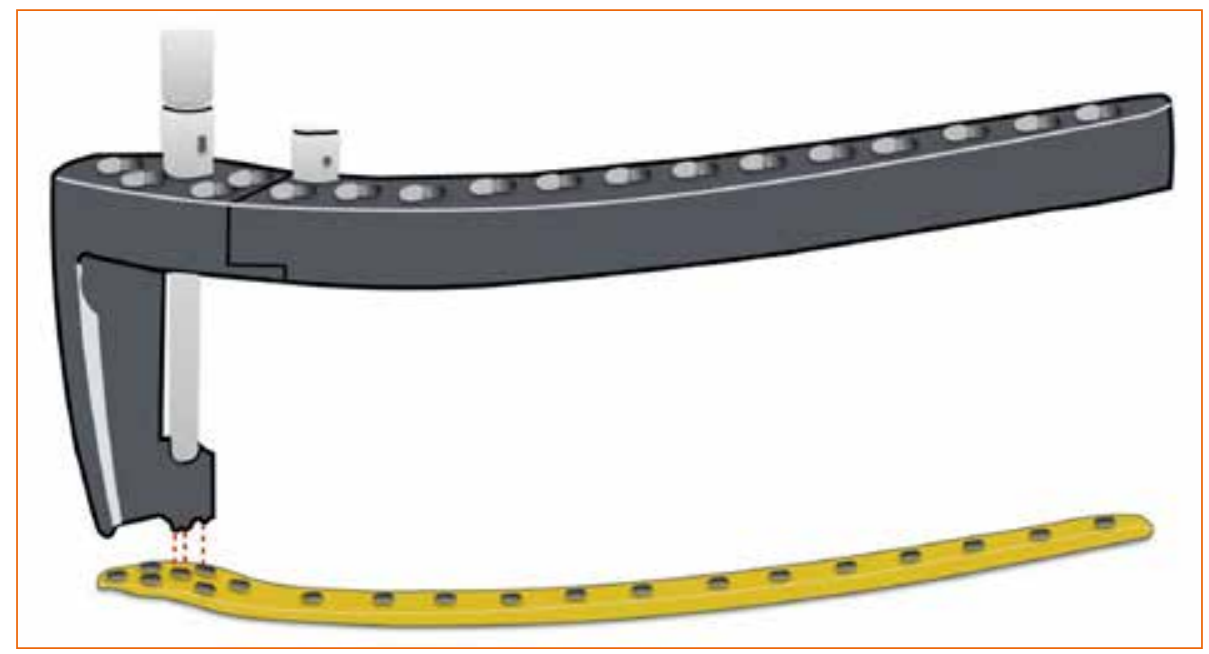

Şekil 11. LISS $^{\circledR}$ minimal invaziv cerrahi ile uyumlu aparat.

Bu cerrahi sırasında hasta pozisyonu olarak, genellikle uzunluğu ve rotasyonu kontrol edebilmek ve karşı ekstremite ile karşılaştırmak amacıyla supin pozisyon kullanılır. Cerrahi masa olarak, ışın geçirgen olmak şartıyla, traksiyon masası ya da düz masa kullanılabilir. Traksiyon, travma masasında masaya ait bot ya da tibial traksiyon çivisi kullanılarak sağlanabileceği gibi düz masada bir asistan yardımıyla gerçekleştirilebilir. Femoral çivi, kırık sahasına gireceği için tercih edilmemelidir. Hangi pozisyon tercih edilirse edilsin, özellikle yaşı hastalarda kırık parçaların bir miktar impaksiyonu iyileşme potansiyelini arttırdığı için, aşırı traksiyondan kaçınılmalıdır. Görüntüleme cihazı ise, hasarlı ekstremitenin karşı tarafından masaya yaklaştırılmalıdır. ${ }^{[3]}$

Ekstremite hazırlığı tamamlandıktan sonra, önemli anatomik bölgelerin ve gerek görülürse kırık parçaların cilt üzerinden kalem ile çizilerek işaretlenmesi yapılmalıdır. Bu işlem, hem cerrahi süresini kısaltmakta ve alınan radyasyon doz miktarını azaltmakta hem de plağın daha doğru bir biçimde yerleştirilmesine kolaylık sağlamaktadır. Bu çizimler arasında, kırık hattının proksimal ve distal sınırları, patella, eklem seviyesi, proksimal bölgedeki femur cisminin seviyesi bulunmaktadır. Böylelikle, yapacağımız mini-insizyonların yerini belirlemek mümkün olmakta, sonrasında da plak yerleşimi daha kolay ve düzgün uygulanabilir hale gelmektedir. ${ }^{[1]}$

İnsizyon olarak, Tip B-C gibi eklem yüzeyi ile ilişkisi olan kırıklarda mediyal ya da lateral parapatellar yaklaşım, eklem yüzeyini ilgilendirmeyen distal femur kırıklarında (Tip A) ise standart lateral yaklaşım kullanılır. Eğer eklem yüzeyini ilgilendiren kırık var ise, uygun insizyon seçilip açık yaklaşım ile anatomik redüksiyon sağlanıp $K$ telleri ile geçici olarak tespit edildikten sonra, uygun kalınlıkta ve parsiyel yivli ya da tam yivli 
spongiyöz vidalarla, lateral kortekse plak yerleştirilmesine engel olmayacak şekilde rijid tespit yapılır. Bu bölgede vida boyları, femur distalinin anatomik özelliği de dikkate alınarak mediyal korteksten ya da eklem yüzeyinden penetrasyona neden olmayacak şekilde seçilmelidir.

Eklemin anatomik redüksiyonu ve tespiti sonrasındaki aşama, distal femoral parça ile metafizodiyafizer bileşkenin uygun dizilim ve tespitini sağlamaktır. Burada, redüksiyonu indirekt olarak yapmak amaçlanmaktadır. Ayrıca, metafizer bölgede bulunan kırık parçaların tam anatomik redüksiyonlarını sağlamaya çalışmak hedeflenmemektedir. Mekanik aksın sağlanması, frontal ve sagittal planda $5^{\circ}$ den az açılanma kabul edilebilir. ${ }^{[3]}$ Indirekt redüksiyon sonrası kabul edilebilir miktarların üzerinde deformasyon var ise, sınırlı açık cerrahi redüksiyon ile bu düzeltilmelidir. Koronal dizilim kablo metodu ile, sagittal dizilim lateral skopi görüntüleri ile, rotasyonel dizilim parçalı kırıklarda her iki tarafın trokanter minörlerinin karşılaştırılması veya basit kırıklarda kortikal kalınlıkların ölçülmesi ile kontrol edilebilir. ${ }^{[13,14]}$ Herhangi bir derecede varus veya $15^{\circ}$ 'nin üzerinde valgusla iyileşmenin post-travmatik artrozla ilişkili olduğunu gösteren çalışmalar mevcuttur. ${ }^{[15]}$

Genelde ilk yapılacak redüksiyon manevrası, hasarIı ekstremiteye uzunlamasına traksiyon uygulamaktır. $\mathrm{Bu}$ işlem sırasında gastrokinemius kasının çekmesinin oluşturduğu kırık bölgesinde açılanma, posteriordan bir destek konularak engellenebilir. Bu desteğin popliteal bölgede değil, kırık hattının distalinde olmasına dikkat edilmelidir. Floroskopi ile kontrol yapıldıktan sonra tespit edilen fleksiyon, rekurvatum ya da farklı deformiteler, yine indirekt yöntemler kullanılarak, kırık hattına en az hasar verecek ve oradaki kırık hematomunu boşaltmayacak şekilde yapılmalıdır. Bu yöntemler arasında distal parçaya konan bir Steinmann çivisi ya da geçici eksternal fiksatörler sayılabilir.

Daha sonra plak, distaldeki insizyondan, vastus lateralis ve rektus femoris kasları arasından açılan submusküler tünelden, periostun üzerinde olmak kaydıyla proksimal diyafize doğru kaydırılır. Genellikle, plağın proksimalde femur diyafizini tam olarak ortaladığından emin olmak için, yukarıdan ikinci bir insizyon yapılabilmektedir. Eğer redüksiyon iyi ise, plak üzerinden distalde santral pin ekleme paralel olacak şekilde gönderilmelidir. Hem ön-arka hem de yan görüntülerde plağın femur distalindeki yeri ve proksimalde femur anterior kortekse paralel olması kontrol edilmelidir. Eğer bu görüntü elde edilememişse, anatomik olmayan dizilim meydana gelmiş demektir ve sonraki dönemde bu durum redüksiyon kaybına veya implant yetmezliklerine zemin hazırlayacaktır. ${ }^{[16]}$
Plak sistemlerinin üzerindeki ikili deliklerden (combi hole) kompresyon deliği, kemik parçasını kemiğe yaklaştırarak redüksiyona yardımcı olur. Redüksiyon sağlandıktan sonra da kilitli vida delikleri aralıklı olarak doldurularak, katı olmayan esnek bir tespit sağlanır. $\mathrm{Bu}$ tespit ve elde edilen göreceli stabilite ile, kırık hattında kal dokusu ile iyileşmeye olanak sağlayan ikincil kemik iyileşmesi elde edilmektedir. ${ }^{[3,8]}$

\section{AMELIYAT SONRASI DÖNEM}

Eklem dahil olsun ya da olmasın, bütün kırıklarda olduğu gibi bu tip kırıklarda da, ameliyat sonrası erken hareket ve rehabilitasyon iyi fonksiyonel sonuç elde etmek için mutlaka gereklidir. Özellikle diz eklemine yakınlığı nedeniyle, gecikmiş mobilizasyon veya eklem hareketi, fonksiyonel diz hareketlerinde ileri derecede kısıtlılığa neden olacaktır. Bu nedenle hastalar, ameliyat sonrası en kısa zamanda eklem hareket açıklığ, kuadriseps ve hamstring germe egzersizlerini yapma konusunda cesaretlendirilmelidirler. Bu hareketler aktif olarak yapılana kadar CPM (Continuous Passive Motion) cihazından yararlanılabilir. Erken dönemde koltuk değnekleri yardımıyla yük vermeden ayağa kaldııılan hastalar, radyolojik ve klinik takiplerine göre karar verilecek şekilde, parsiyel yük vermeye başlayabilirler. Tam yük vermek içinse, özellikle eklem yüzeyini de ilgilendiren kompleks ve çok parçalı kırıklarda, radyolojik olarak kaynamadan emin olmak gerekmektedir. ${ }^{[7,15]}$

\section{DISTAL FEMUR KIRIKLARINDA PLAKLA MINIMAL INVAZIV OSTEOSENTEZ ILE YAPILMIŞ ÇALIŞMALAR}

Literatürde, distal femur kırıklarında tespit şeklinin ve kullanılan farklı implantların karşılaştırıldığı pek çok klinik, anatomik ve biyomekanik çalışmada, elde edilen sonuçların genellikle birbirine yakın olduğunu bildiren veriler vardır. Staoffel ve ark., 36 kadavra ve 60 kompozit kemik üzerinde yapmış oldukları biyomekanik çalışmada, kompresyon plağı, internal fiksatör $\left(\right.$ LiSS $^{\circledR}$ ) ve kombine plakları, aksiyel ve torsiyonel yüklenme altındaki dayanıklılıkları, plastik deformasyonları ve tespit gücü açısından karşılaştırmışlardır. Bu çalışmada, LISS ${ }^{\circledR}$ plağının aksiyel yük altında parçalı kırıklarda kompresyon plağı ile benzer tespit sağlamasına rağmen, redüksiyon kolaylığı göz önünde bulundurulduğunda daha iyi bir teknik olduğu belirtilmiştir. Torsiyonel yüklenme altında ise kompresyon plağı, LISS $^{\circledR}$ plağından daha etkili bulunmuştur. ${ }^{[17]}$

Markmiller ve ark., 32 distal femur kırı̆ı hastasının yarısını LISS ${ }^{\circledR}$ diğer yarısını ise DFN (distal femoral nail) ile tedavi etmiş ve iki grup arasında fonksiyonel ve radyolojik fark olmadığını belirtmişlerdir. ${ }^{[18]}$ Zlowodzki 
ve ark., 1989-2005 yılları arasını kapsayan sistematik derlemelerinde, 1670 distal femur kırığının intramedüller çivi (antegrad ve retrograd), kilitli internal fiksatör (LISS ${ }^{\circledR}$ ), kompresyon plağı (açılı kamalı plak, DCS, kondiler destek plağı) ve eksternal fiksatör ile tespit edildiğini bildirmişlerdir. Kaynamama oranları; LISS ${ }^{\circledR}$ 'de $\% 5,5$ iken, retrograd çivilemede $\% 5,3$, antegrad çivilemede $\% 8,3$, kompresyon plağında $\% 6,3$ ve eksternal tespitte \%7,2 bulunmuştur. İmplant yetmezlik oranları; LISS ${ }^{\circledR}$ de $\% 4,9$ iken, retrograd çivilemede $\% 3,2$, antegrad çivilemede \%3,7, kompresyon plağında \%2,6 ve eksternal tespitte \%1,5 bulunmuştur. İkincil cerrahi gereksinimleri; LISS ${ }^{\circledR}$ de \%16,2 iken, retrograd çivilemede $\% 24,2$, antegrad çivilemede $\% 23,1$, kompresyon plağında \%12,7 ve eksternal tespitte \%30,6 bulunmuştur. ${ }^{[1]}$

Literatürde, distal femur kırıklarında minimal invaziv plaklama, sadece diğer tespit yöntemleri ile değil aynı zamanda kendi içindeki uygulama farklılıkları açısından da karşılaştırılmıştır. Khalafi ve ark., AO/ OTA 33-A3 kırık kemik modellerinde yapmış olduğu biyomekanik çalışmada, LISS $^{\circledR}$ plağın uygun olan iç rotasyonda yerleştirilmesi ile uygun olmayan dış rotasyonda yerleştirilmesini biyomekanik olarak karşılaştırılmışlardır. Distal femur kırık tespitinde LISS $^{\circledR}$ plağın doğru yerleştirilmesinin aksiyel yüklenmede dayanılıklılığı arttırdığı, kemik-vida arayüzeyindeki plastik (irreversible) deformasyonu azalttığı ve mekanik stabilitenin artmasını sağladığı ifade edilmiştir. ${ }^{[19]}$ Wilkens ve ark.'nın AO/OTA 33-A3 kırık kemik modellerinde yapmış oldukları biyomekanik çalışmada ise, distal femur kırıklarında poli-aksiyel ve uni-aksiyel kilitlemeye izin veren plaklar biyomekanik açıdan karşılaştırılmış ve poli-aksiyel kilitleme yapan plakların bu kırıklarda daha sağlam bir tespit seçeneği sunduğu bildirilmiştir. Sürtünmeli kilitleme mekanizmasının, değişken vida seçeneği sağlarken açısal stabilitenin korunmasını da sağladığı belirtilmiştir. ${ }^{[20]}$

Minimal invaziv plaklama aynı zamanda diz artroplastisi protez çevresi kırık tedavisinde de iyi bir alternatif oluşturmuştur. Ricci ve Borrelli'nin yapmış oldukları geriye dönük çalışmada, periprostetik femur kırıklarında biyolojik tespit sonuçları incelenmiş ve 30 suprakondiler femur kırı̆̆ hastasının sadece birinde kaynamama bildirilmiştir. Bu çalışmada, protez çevresi kırıklarda greft ihtiyacı ve açı cerrahinin rutin ihtiyaç olmadığı, lateral kilitli plak ile biyolojik tespit yapıldığında hastaların ek cerrahiye ihtiyaç duymadan iyileşeceği belirtilmiştir. ${ }^{[21]}$

Wähnert ve ark.'nın çeşitli tiplerde femoral çiviler ile kilitli plakların biyomekanik güçlerini değerlendirdikleri deneysel çalışmada, kilitli plakların diğer implantlara göre torsiyonel yüklenmelerde daha stabil olduğu bulunmuştur. Buna karşın, aksiyel yüklenmelerde suprakondiler çiviler daha dayanıklı bulunmuştur. Bu nedenle yazarlar, daha erken mobilize edilecek genç hastalarda suprakondiler çivileri, osteoporotik hastalarda ise kilitli plakları önermişlerdir. ${ }^{[22]}$

\section{KAYNAKLAR}

1. Zlowodzki M, Bhandari M, Marek DJ, Cole PA, Kregor PJ. Operative treatment of acute distal femur fractures: systematic review of 2 comparative studies and 45 case series (1989 to 2005). J Orthop Trauma 2006;20(5):366-71. Crossref

2. Hoffmann MF, Jones CB, Sietsema DL, Tornetta P, Koenig SJ. Clinical outcomes of locked plating of distal femoral fractures in a retrospective cohort. J Orthop Surg Res 2013;8(1):43. Crossref

3. Ehlinger $M$, Adam $P$, Abane $L$, Arlettaz $Y$, Bonnomet $F$. Minimally-invasive internal fixation of extra-articular distal femur fractures using a locking plate: tricks of the trade. Orthop Traumatol Surg Res 2011;97(2):201-5. Crossref

4. Park J, Lee JH. Comparison of retrograde nailing and minimally invasive plating for treatment of periprosthetic supracondylar femur fractures (OTA 33-A) above total knee arthroplasty. Arch Orthop Trauma Surg 2016;136(3):331-8. Crossref

5. Marsh JL, Slongo TF, Agel J, Broderick JS, Creevey W, DeCoster TA, Prokuski L, Sirkin MS, Ziran B, Henley B, Audigé L. Fracture and dislocation classification compendium - 2007: Orthopaedic Trauma Association classification, database and outcomes committee. J Orthop Trauma 2007;21(10 Suppl):S1-6. Crossref

6. Azar FM, Canale ST, Beaty JH. Fractures of the Lower Extremity, Chap. 54. In: Daugherty K, Jones L, editors. Campbell`s Operative Orthopaedics, 13th ed. Canada: CV Mosby; 2017. p.2784.

7. Khan AM, Tang QO, Spicer D. The Epidemiology of Adult Distal Femoral Shaft Fractures in a Central London Major Trauma Centre Over Five Years. Open Orthop J 2017;11(1):1277-91. Crossref

8. Ehlinger M, Ducrot G, Adam P, Bonnomet F. Distal femur fractures. Surgical techniques and a review of the literature. Orthop Traumatol Surg Res 2013;99(3):353-60. Crossref

9. Kregor PJ, Stannard JA, Zlowodzki M, Cole PA. Treatment of distal femur fractures using the less invasive stabilization system: surgical experience and early clinical results in 103 fractures. J Orthop Trauma 2004;18(8):509-20. Crossref

10. Gerber C, Mast JW, Ganz R. Biological internal fixation of fractures. Arch Orthop Trauma Surg 1990;109(6):295-303. Crossref

11. Babst R, Bavonratanavech S, Pesantez R. Minimally Invasive Plate Osteosynthesis, 2nd expanded ed. New York: Thieme; 2012.

12. Kanabar $P$, Kumar $V$, Owen $P$, Rushton $N$. Less Invasive Stabilisation System Plating for Distal Femoral Fractures. J Orthop Surg 2007;15(3):299-302. Crossref

13. Kim J-W, Oh C-W, Oh J-K, Park I-H, Kyung H-S, Park K-H, Yoon S-D, Kim S-M. Malalignment after minimally invasive plate osteosynthesis in distal femoral fractures. Injury 2017;48(3):751-7. Crossref

14. Krettek C, Schandelmaier P, Nliclau T, Tscherne H. Minimally invasive percutaneous plate osteosynthesis (MIPPO) using the DCS in proximal and distal femoral fractures. Injury 1997;28(Suppl 1):A20-30. Crossref 
15. Gwathmey FW, Jones-Quaidoo SM, Kahler D, Hurwitz S, Cui Q. Distal femoral fractures: current concepts. J Am Acad Orthop Surg 2010;18(10):597-607. Crossref

16. Ehlinger $M$, Adam $P$, Arlettaz $\mathrm{Y}$, Moor BK, DiMarco A, Brinkert D, Bonnomet F. Minimally-invasive fixation of distal extra-articular femur fractures with locking plates: limitations and failures. Orthop Traumatol Surg Res 2011;97(6):66874. Crossref

17. Stoffel K, Lorenz K-U, Kuster MS. Biomechanical considerations in plate osteosynthesis: the effect of plate-tobone compression with and without angular screw stability. J Orthop Trauma 2007;21(6):362-8. Crossref

18. Markmiller M, Konrad G, Südkamp N. Femur-LISS and distal femoral nail for fixation of distal femoral fractures: are there differences in outcome and complications? Clin Orthop Relat Res 2004;426:252-7. Crossref
19. Khalafi A, Curtiss S, Hazelwood S, Wolinsky P. The effect of plate rotation on the stiffness of femoral LISS. a mechanical study. J Orthop Trauma 2006;20(8):542-6. Crossref

20. Wilkens KJ, Curtiss S, Lee MA. Polyaxial Locking Plate Fixation in Distal Femur Fractures: A Biomechanical Comparison. J Orthop Trauma 2008;22(9):624-8. Crossref

21. Ricci WM, Borrelli J. Operative management of periprosthetic femur fractures in the elderly using biological fracture reduction and fixation techniques. Injury 2007;38(3):53-8. Crossref

22. Wähnert D, Hoffmeier $K$, Fröber $R$, Hofmann GO, Mückley T. Distal femur fractures of the elderly -different treatment options in a biomechanical comparison. Injury 2011;42(7):655-9. Crossref 